\title{
Multimodal Treatment of Vasoactive Intestinal Polypeptide-producing Pancreatic Neuroendocrine Tumors with Liver Metastases
}

\author{
Mari Iwasaki, Kouhei Tsuchida, Hidehito Jinnai, Toshinori Komatsubara, Takahiro Arisaka, \\ Misako Tsunemi, Masakazu Nakano, Makoto Iijima and Hideyuki Hiraishi
}

\begin{abstract}
A 53-year-old man presented with diarrhoea and hypokalaemia and was diagnosed with a neuroendocrine tumour of unknown origin with multiple liver metastases. Somatostatin analogues led to a reduction in the size of the tumours and improvement of his symptoms. However, after several years, the tumours grew in size, and the patient's clinical symptoms recurred. The patient underwent transcatheter arterial embolization (TAE) of the hepatic artery to treat the liver metastases. Immediately after embolization, the symptoms disappeared. Although the patient had an unresectable vasoactive intestinal polypeptide-producing neuroendocrine tumour, the endocrine symptoms were able to be controlled with chemotherapy and TAE, resulting in a longterm survival.
\end{abstract}

Key words: neuroendocrine tumours, VIPoma, pancreatic neoplasms, liver metastases, transcatheter arterial embolization

(Intern Med 56: 517-522, 2017)

(DOI: 10.2169/internalmedicine.56.7512)

\section{Introduction}

A vasoactive intestinal polypeptide (VIP)-producing neuroendocrine tumour (VIPoma) is an extremely rare tumour that presents with symptoms such as watery diarrhoea and hypokalaemia as a result of VIP overproduction. Surgery is generally the preferred treatment, but moleculartargeting drugs such as everolimus and sunitinib have been recently developed for cases of advanced disease. Furthermore, for cases where radical resection is impossible, multimodal therapy including surgical reduction of the tumour mass is now recommended (1). We treated a case in which good disease control was achieved through transcatheter arterial embolization (TAE) of liver metastases in a patient with a pancreatic VIPoma who had developed somatostatin resistance. We report the course of this patient's treatment, which may be useful when selecting a therapy for VIPoma that is difficult to treat surgically.

\section{Case Report}

The case patient was a 53-year-old man. He presented at his local doctor's office with a chief complaint of watery diarrhoea occurring $\geq 10$ times per day, which had persisted for approximately 6 months, in combination with epigastric discomfort. Blood tests revealed liver dysfunction with an aspartate aminotransferase level of 42 IU/L (normal range: 10$40 \mathrm{IU} / \mathrm{L})$ and alanine aminotransferase level of $47 \mathrm{IU} / \mathrm{L}$ (normal range: 5-40 IU/L), a serum potassium concentration of $2.4 \mathrm{mmol}$ (range: $3.5-5.0 \mathrm{mmol}$ ), and a urea nitrogen level of $21 \mathrm{mg} / \mathrm{dL}$ (range: $6-20 \mathrm{mg} / \mathrm{dL}$ ) (Table 1). Upper and lower gastrointestinal endoscopy did not reveal any abnormalities. Computed tomography (CT) showed multiple tumours in both lobes of the liver (Fig. 1a-1, 1a-2). The patient was therefore referred to our hospital for further evaluation in April 2010.

Contrast-enhanced abdominal CT performed at our hospital revealed a hypervascular hepatic mass that stained in the

Department of Gastroenterology, Dokkyo Medical University, Japan

Received for publication April 3, 2016; Accepted for publication July 11, 2016

Correspondence to Dr. Kouhei Tsuchida, tsuchida@dokkyomed.ac.jp 
Table 1. Summary of Laboratory Data.

\begin{tabular}{|c|c|c|c|c|c|}
\hline \multicolumn{2}{|c|}{$<$ Hematology $>$} & \multicolumn{2}{|c|}{$<$ Blood chemistry $>$} & \multicolumn{2}{|c|}{$<$ Coagulation profile $>$} \\
\hline WBC & $6.60 \times 10^{9} / \mathrm{L}$ & $\mathrm{TP}$ & $6.5 \mathrm{~g} / \mathrm{dL}$ & \multirow[t]{2}{*}{$\mathrm{PT} \%$} & \multirow[t]{2}{*}{$63 \%$} \\
\hline NEUTRO & $79.10 \%$ & Alb & $3.7 \mathrm{~g} / \mathrm{dL}$ & & \\
\hline EOSINO & $1.10 \%$ & AST & $42 \mathrm{U} / \mathrm{L}$ & \multicolumn{2}{|c|}{$<$ Hormone profile $>$} \\
\hline $\mathrm{RBC}$ & $4.27 \times 10^{12} / \mathrm{L}$ & ALT & $47 \mathrm{U} / \mathrm{L}$ & Insulin & $4 \mu \mathrm{U} / \mathrm{mL}$ \\
\hline $\mathrm{Hb}$ & $13.1 \mathrm{~g} / \mathrm{dL}$ & LDH & $319 \mathrm{U} / \mathrm{L}$ & \multicolumn{2}{|c|}{$(1-17 \mu \mathrm{U} / \mathrm{mL})$} \\
\hline $\mathrm{Ht}$ & $37.70 \%$ & $\gamma$-GTP & $19 \mathrm{U} / \mathrm{L}$ & Gastrin & $66 \mathrm{pg} / \mathrm{mL}$ \\
\hline \multirow[t]{2}{*}{ Plt } & $16.3 \times 10^{4} / \mu \mathrm{L}$ & T-Bil & $0.6 \mathrm{mg} / \mathrm{dL}$ & \multicolumn{2}{|c|}{ (Upper limit 200 pg/mL) } \\
\hline & & Cre & $0.58 \mathrm{mg} / \mathrm{dL}$ & $\mathrm{ACTH}$ & $77.6 \mathrm{pg} / \mathrm{mL}$ \\
\hline \multicolumn{2}{|c|}{$<$ Tumor maker $>$} & BUN & $21 \mathrm{mg} / \mathrm{dL}$ & \multicolumn{2}{|c|}{ (Upper limit 46 pg/mL) } \\
\hline CEA & $2.7 \mathrm{ng} / \mathrm{mL}$ & $\mathrm{Na}$ & $141 \mathrm{mEq} / \mathrm{L}$ & VIP & $553 \mathrm{pg} / \mathrm{mL}$ \\
\hline CA19-9 & $4 \mathrm{U} / \mathrm{mL}$ & $\mathrm{K}$ & $2.4 \mathrm{mEq} / \mathrm{L}$ & \multirow{2}{*}{\multicolumn{2}{|c|}{ (Upper limit 100 pg/mL) }} \\
\hline AFP & $4 \mathrm{ng} / \mathrm{mL}$ & $\mathrm{Cl}$ & $97 \mathrm{mEq} / \mathrm{L}$ & & \\
\hline PIVKA2 & $37 \mathrm{mAU} / \mathrm{mL}$ & $\mathrm{Ca}$ & $8.8 \mathrm{mg} / \mathrm{dL}$ & & \\
\hline
\end{tabular}

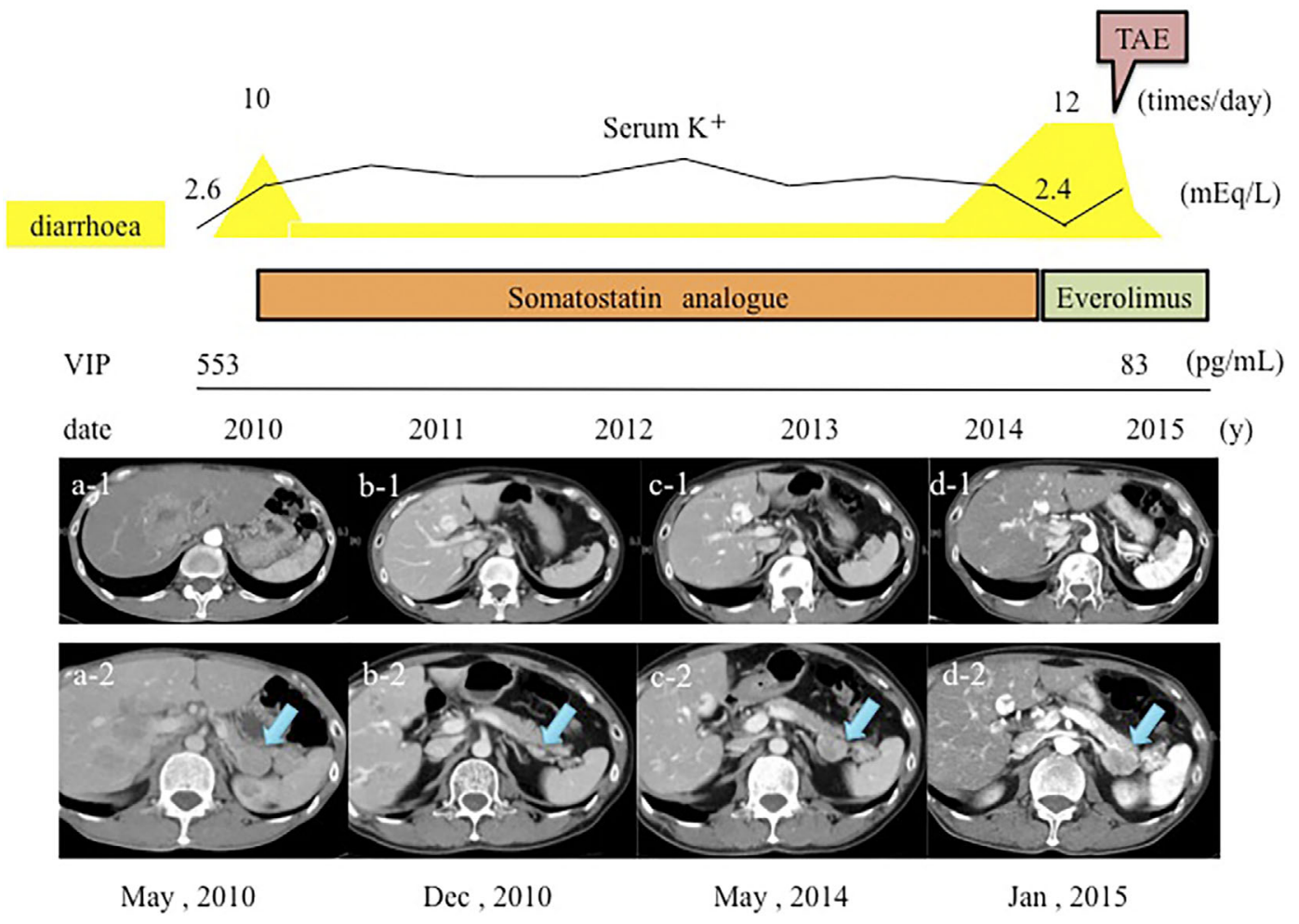

Figure 1. Clinical course. a-1: Multiple hypervascular tumours were seen in both the lobes of the liver. a-2: A tumour $30 \mathrm{~mm}$ in diameter could be seen in the tail of the pancreas. b-1: Computed tomography revealed decreased sizes of all of the tumours from 2010 after the administration of octreotide. b-2: Marked reduction was also seen in the size of the tumour in the pancreatic tail. c-1: A slight increase in the size of the liver tumours was seen on computed tomography from 2014, when symptoms recurred. c-2: The tumour in the pancreas also increased in size, which was comparable to that of the first image obtained 4 years previously. d-1: After the administration of everolimus, the metastatic liver tumour shrank in size. d-2: The tumour in the pancreas did not shrink in size.

early arterial phase in both lobes. Although the hepatic mass was suspected to be a metastatic tumour, the primary tumour was not identified at this point, with the mass identified at the tail of the pancreas considered to be a swollen lymph node. Fluorodeoxyglucose positron emission tomography (FDG-PET) did not clearly demonstrate a primary tumour. Percutaneous hepatic mass biopsy confirmed the growth of atypical cells with an abnormal structure. The Ki-67 index 


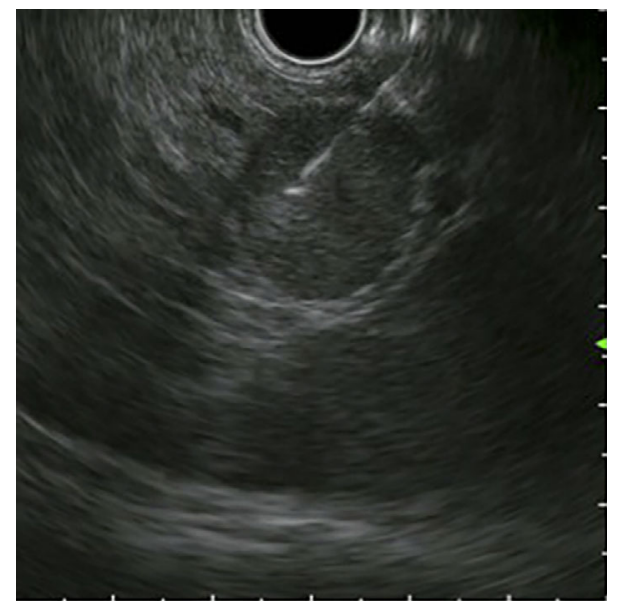

Figure 2. Endosonographic findings of a tumour in the pancreatic tail. A hypoechoic tumour $20 \mathrm{~mm}$ in diameter with distinct borders was seen in the pancreatic tail on endoscopic ultrasound.

was $5 \%$ positive, and immunostaining was positive for synaptophysin and chromogranin. Serum vasoactive intestinal peptide (VIP) was high at $553 \mathrm{pg} / \mathrm{mL}$ (normal $\leq 100 \mathrm{pg} / \mathrm{mL}$ ). Because the mass was diagnosed as a functional neuroendocrine tumour (NET; VIPoma) with an unknown primary, treatment with an analogue of somatostatin (subcutaneous injection of Sandostatin ${ }^{\circledR} 50 \mu \mathrm{g}$, twice daily) was initiated in June 2010. The mass decreased in size, and the clinical symptoms improved.

Thereafter, maintenance therapy with a long-acting form of octreotide (Sandostatin LAR $^{\circledR}, 30 \mathrm{mg}$ intramuscularly once monthly) was prescribed, which sustained the improvement in symptoms and tumour size on CT (Fig. 1b-1, 1b-2). Although we considered surgical treatment, the patient did not consent to this procedure, and pharmacological treatment was thus continued.

However, in May 2014, 4 years after the initial treatment, the patient once again began to experience watery diarrhoea $\geq 10$ times per day. A CT examination at that time revealed the enlargement of multiple hypervascular tumours in both lobes of the liver and a tumour in the pancreatic tail (Fig. 1c-1, 1c-2). In July of the same year, endoscopic ultrasound (EUS) demonstrated an oval, 28-mm-diameter, solid mass with a clear boundary in the tail of the pancreas. Endoscopic ultrasonography-guided fine-needle aspiration (EUS-FNA) of the mass showed atypical cells with naked nuclei and eccentric nuclei on Hematoxylin and Eosin (H\&E) staining. The Ki-67 index was $10 \%$ positive, and immunostaining was positive for synaptophysin, chromogranin, as well as VIP. A diagnosis of pancreatic NET (P-NET; VIPoma) was made, with a World Health Organization (WHO) classification of G2 (Fig. 2, 3).

The patient was thought to have developed resistance to octreotide and was started on everolimus (Afinitor ${ }^{\circledR}$ at 10 $\mathrm{mg}$ daily [2 capsules per dose]) in July 2014. After the administration of everolimus, the metastatic liver tumour decreased in size. However, there was no notable improvement in the watery diarrhoea or hypokalaemia. To relieve his endocrine symptoms, TAE of the hepatic artery was performed for the liver metastases.

Abdominal angiography in September 2014 revealed at least three deeply stained tumours in the right hepatic artery region and multiple small tumour stains around the largest tumour in S6 of the liver (Fig. 4). TAE was performed using a permanent embolic agent (Microspheres ${ }^{\circledR}$ ) and gelatine sponge. The diarrheal symptoms disappeared the following day, and the serum VIP concentration markedly dropped to $83 \mathrm{pg} / \mathrm{mL}$. Four months later, the symptoms recurred, and TAE was repeated to treat the remaining liver metastases. The patient continues to take oral everolimus, his symptoms have subsided, and the reduction in tumour size is being maintained. Switching treatment to sunitinib was considered. However, because the liver tumour mass had decreased in size, we opted for continuation of everolimus treatment and management of the endocrine symptoms with TAE (Fig. 1d-1, 1d-2).

\section{Discussion}

VIPoma was first reported by Verner and Morrison in 1958. The majority of VIPomas are NETs originating in the pancreas (2). The incidence is extremely low at just 1 in 10 million people per year (3). According to a 2010 survey by Ito et al. in Japan, VIPomas accounted for $0.6 \%$ of the PNETs overall, with distant metastases present at the time of diagnosis in $80 \%$ of cases (4). The VIP produced by these tumours causes the characteristic watery diarrhoea, hypokalaemia, and achlorhydria syndrome (5). The disease is diagnosed on the basis of these symptoms, an elevated serum VIP concentration, and tissue immunostaining. In recent years, EUS-FNA has been increasingly used, as it allows for a histopathological diagnosis but is less invasive than conventional open or laparoscopic biopsy. In terms of FNA histological diagnosis, results have been favourable, with a reported sensitivity of $82.6-100 \%$ and a diagnostic accuracy of approximately 83.3-97.3\%. FNA offers a high diagnostic performance for detecting P-NETs (6-11). However, because reports have indicated that lesions in the head of the pancreas and tumour masses rich in fibrosis are difficult to diagnose using FNA (10), a multiple-modality approach is required for diagnosing such tumour masses. Furthermore, the grade classification of P-NETs is determined by the mitotic rate and Ki-67 index on a pathological examination. Because of the unevenness of the Ki-67 index within the tumour masses, it is preferable to base the grading of NET on $\geq 2000$ cells from an FNA sample (11).

Other tests for NETs include somatostatin receptor scintigraphy and tetraazacyclododecane-tetraacetic acid-modified Tyr-octreotide-PET, which have high positivity rates for detecting highly differentiated NETs. FDG-PET is very sensitive for undifferentiated neuroendocrine carcinomas with a high proliferative capacity (2010 WHO NET classification).

Functional NETs are treated surgically when there are no 

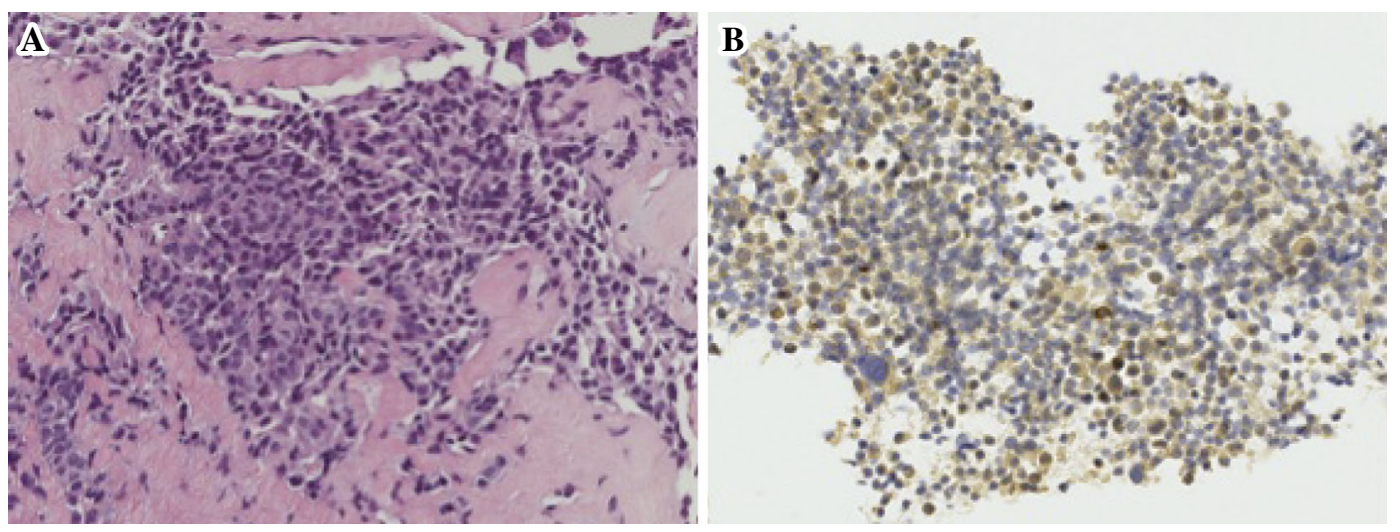

Figure 3. Histopathologic features of the pancreatic neuroendocrine tumour. A: 40x, Approximately $10 \%$ of the tumour cells appeared MIB-1 positive on Hematoxylin and Eosin staining, so the tumour was classified as G2. B: 40x, On VIP immunostaining, the cytoplasm was stained granularly and diffusely.

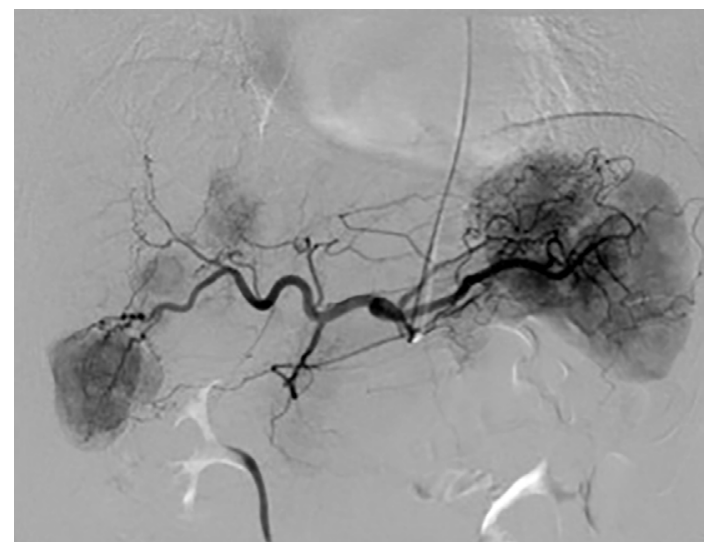

Figure 4. Image of TAE for liver metastasis. Hypervascular tumour staining was seen in three places in the right hepatic artery region.

liver or distant metastases. In cases accompanied by liver and/or distant metastasis, for which a radical cure cannot be anticipated, surgery to reduce the size of the original tumour by at least $90 \%$ appears to be effective from the viewpoint of alleviating symptoms (12). Furthermore, for P-NETs with distant metastases, it has been reported that resection of the primary tumour is effective for prolonging survival. However, because there are few clinical studies comparing cases with and without primary tumour resection, this issue remains unresolved. A systematic review concluded that resection of the primary tumour for patients with P-NETs and unresectable liver metastases should be considered only in high-volume referral centres with strict selection criteria and in a multidisciplinary setting (13). Thus, resection of the primary tumour should be considered for functional P-NETs with multiple liver metastases, such as in the present case. However, because our patient refused surgery, we selected medication-based treatment instead.

With unresectable functional NETs, somatostatin analogues are useful for treating the symptoms (14-16). However, resistance may develop as a result of the down- regulation of somatostatin receptors following the long-term use of the drug $(17,18)$. In the present case, the patient developed resistance to octreotide over the course of four years, thus leading to symptom recurrence. The moleculartargeting drugs everolimus and sunitinib have recently been found to be effective antitumour drugs against primitive NETs (G1/G2) $(19,20)$. A phase III comparative trial (RADIANT-3) demonstrated the effectiveness of everolimus, with treated subjects showing a progression-free survival of 11 months, compared with 4.6 months in those taking the placebo (19). Sunitinib was similarly found to offer better progression-free survival than a placebo (11.4 vs. 5.5 months) (20). TAE and transcatheter arterial chemoembolization (TACE) have also been found to be effective as local treatments for NET liver metastases (7). TAE in particular may be about $90 \%$ effective in providing complete or partial relief of endocrine symptoms, an effect reported to last 6-27 months (21). TAE led to an improvement in our patient's symptoms as well; however, symptom recurrence after four months necessitated repeat TAE. TAE may thus be an effective treatment for liver metastases, although the results may be only temporary, and instances of recurrence may require treatment be conducted repeatedly.

During the 30-year period from 1985 to 2015, we identified 6 cases of VIPoma in the English literature (based on a PubMed search) that were managed by non-surgical multidisciplinary modalities alone (22-26). These six cases plus ours are summarized in Table 2. All patients had functional NET with watery diarrhoea and were found to have liver metastases. Survival for at least 10 years was achieved in 3 cases with drugs or drugs plus TACE. Two patients died: one with severe hypokalaemia associated with watery diarrhoea (22) and one whose increasingly severe diarrhoea could no longer be controlled, despite the use of a somatostatin analogue and repeated TACE (24). The fact that exacerbation of symptoms was the cause of death in two cases and that survival of at least 10 years was seen in other cases as a result of a combination of chemotherapy and TACE 
Table 2. Unresectable VIPoma Reported Between1985 and 2015.

\begin{tabular}{|c|c|c|c|c|c|c|c|c|c|c|}
\hline Reference & Year & Age & Gender & Symptoms & Metatases & Diagnosis & Treatment & $\begin{array}{l}\text { Efficient symptom } \\
\text { relief }\end{array}$ & Outcome & $\begin{array}{c}\text { Time since diagnosis, } \\
\text { mos }\end{array}$ \\
\hline 22 & 1988 & 55 & M & $\begin{array}{l}\text { watery diarrhea, } \\
\text { hypokalemia }\end{array}$ & liver & $\mathrm{CT}$, needle biopsy & 5FU, streptozotocin & No & died & 8 \\
\hline 23 & 1989 & 60 & F & $\begin{array}{l}\text { watery diarrhea, } \\
\text { hypokalemia, } \\
\text { weight loss }\end{array}$ & liver & CT & somatostatin analog & Yes & alive & 12 \\
\hline 24 & 1999 & 53 & M & $\begin{array}{l}\text { watery diarrhea, } \\
\text { hypokalemia }\end{array}$ & liver & CT & somatostatin analog, TACE & Yes & alive & 144 \\
\hline 24 & 1999 & 45 & M & watery diarrhea & liver & CT & $\begin{array}{l}\text { somatostatin analog, } 5 \mathrm{FU}, \\
\text { streptozotocin, TACE }\end{array}$ & Yes & died & 144 \\
\hline 25 & 2001 & 32 & M & $\begin{array}{l}\text { watery diarhrea, } \\
\text { hypokalemia }\end{array}$ & liver & MRI & n.d & No & n.d & n.d \\
\hline 26 & 2009 & 56 & M & watery diarrhea & liver & CT & $\begin{array}{l}\text { somatostatin analog, } 5 \mathrm{FU} \text {, } \\
\text { methotrexate }\end{array}$ & Yes & alive & 144 \\
\hline present case & 2014 & 53 & M & $\begin{array}{l}\text { watery diarrhea, } \\
\text { hypokalemia }\end{array}$ & liver & CT, EUS-FNA & somatostatin analog, TAE & Yes & alive & 60 \\
\hline
\end{tabular}

n.d: not described

suggests that control of endocrine symptoms in unresectable VIPoma is important to improve the prognosis. In the present case, the endocrine symptoms are currently being controlled with oral everolimus, after TAE twice for multiple liver metastases; the patient appears to have a good longterm survival. Furthermore, as the main lesions responsible for the endocrine symptoms in our patient are likely the liver metastases, if symptoms recur in the future, we expect that we will be able to control the disease with aggressive TAE. The successful control of endocrine symptoms with sunitinib has been reported in similar cases (27). Thus, if combination treatment with everolimus and TAE is problematic, switching of the drug regimen may be necessary.

In conclusion, surgery is certainly the best current treatment for VIPoma if it can be completely resected. However, in unresectable cases, non-surgical multidisciplinary treatment that controls endocrine symptoms may result in a long-term survival.

The authors state that they have no Conflict of Interest (COI).

\section{Acknowledgement}

We are grateful to all of the clinicians involved in the management and treatment of the patients.

\section{References}

1. Abood GJ, Go A, Malhotra D, Shoup M. The surgical and systemic management of neuroendocrine tumors of the pancreas. Surg Clin North Am 89: 249-266, 2009.

2. Park SK, O'Dorisio MS, O'Dorisio TM. Vasoactive intestinal polypeptide-secreting tumors: biology and therapy. Baillieres Clin Gastroenterol 10: 673-696, 1996.

3. Friesen SR. Update on the diagnosis and treatment of rare neuroendocrine tumors. Surg Clin North Am 67: 379-393, 1987.

4. Ito $\mathrm{T}$, Igarashi $\mathrm{H}$, Nakamura $\mathrm{K}$, et al. Epidemiological trends of pancreatic and gastrointestinal neuroendocrine tumors in Japan: a nationwide survey analysis. J Gastroenterol 50: 58-64, 2015.

5. Verner JV, Morrison AB. Islet cell tumor and a syndrome of refractory watery diarrhea and hypokalemia. Am J Med 9: 374-380, 1958.

6. Andengh JC, de Paulo GA, Ferrari AP. EUS-guided FNA in the diagnosis of pancreatic neuroendocrine tumors before surgery. Gastrointest Endosc 60: 378-384, 2004.

7. Figueiredo FA, Giovannini M, Monges G, et al. EUS-FNA predicts 5-year survival in pancreatic endocrine tumors. Gastrointest Endosc 70: 907-914, 2009.

8. Pais SA, Al-Haddad M, Mohamadnejad M, et al. EUS for pancreatic neuroendocrine tumors: a single-center, 11-year experience. Gastrointest Endosc 71: 1185-1193, 2010.

9. Gornals J, Varas M, Catala I, et al. Definitive diagnosis of neuroendocrine tumors using fine-needle aspiration-puncture guided by endoscopic ultrasonography. Rev Esp Enferm Dig 103: 123-128, 2011.

10. Hijioka S, Hara K, Mizuno N, et al. Diagnostic performance and factors influencing the accuracy of EUS-FNA of pancreatic neuroendocrine neoplasms. J Gastroenterol 51: 923-930, 2016.

11. Hasegawa T, Yamao K, Hijioka S, et al. Evaluation of Ki-67 index in EUS-FNA specimens for the assessment of malignancy risk in pancreatic neuroendocrine tumors. Endoscopy 46: 32-38, 2014.

12. Bertani E, Fazio N, Botteri E, et al. Resection of the primary pancreatic neuroendocrine tumor in patients with unresectable liver metastases: possible indications for a multimodal approach. Surgery 155: 607-614, 2014.

13. Capurso G, Bettini R, Rinzivillo M, Boninsegna L, Delle Fave G, Falconi M. Role of resection of the primary pancreatic neuroendocrine tumour only in patients with unresectable metastatic liver disease: a systematic review. Neuroendocrinology 93: 223-229, 2011.

14. Maton PN, Gardner JD, Jensen RT. Use of long-acting somatostatin analog SMS 201-995 in patients with pancreatic islet cell tumors. Dig Dis Sci 34 (3 Suppl): 28S-39S, 1989.

15. Arnold R, Frank M, Kajdan U. Management of gastroenteropancreatic endocrine tumors: the place of somatostatin analogues. Digestion 55: 107-113, 1994.

16. Debas HT, Gittes G. Somatostatin analogue in functioning neuroendocrine gut tumors. Digestion 54: 68-71, 1993.

17. Koelz A, Kraenzlin M, Gyr K, et al. Escape of the response to a 
long-acting somatostatin analogue (SNIS 201-995) in patients with VIPoma. Gastroenterology 92: 527-531, 1987.

18. Lamberts SW, Pieters GF, Metselaar HJ, Ong GL, Tan HS, Reubi JC. Development of resistance to a long-acting somatostatin analogue during treatment of two patients with metastatic endocrine pancreatic tumors. Acta Endocrinol 119: 561-566, 1988.

19. Yao JC, Shah MH, Ito T, et al. Everolimus for advanced pancreatic neuroendocrine tumors. N Engl J Med 364: 514-523, 2011.

20. Raymond E, Dahan L, Raoul JL, et al. Sunitinib malate for the treatment of pancreatic neuroendocrine tumors. N Engl J Med 364: 501-513, 2011.

21. Vogl TJ, Naguib NN, Zangos S, Eichler K, Hedayati A, Nour-Eldin NE. Liver metastases of neuroendocrine carcinomas: interventional treatment via transarterial embolization, chemoembolization and thermal ablation. Eur J Radiol 72: 517-528, 2009.

22. Cavallo-Perin P, De Paoli M, Guiso G, et al. A combined glucagonoma and VIPoma syndrome. First pathologic and clinical report. Cancer 62: 2576-2579, 1988.

23. Christensen C. The somatostatin analogue SMS 201-995 in longterm treatment of vipoma. Acta Chir Scand 155: 541-543,
1989.

24. Nguyen HN, Backers B, Lmmert F, et al. Long-term survival after diagnosis of hepatic metastatic VIPoma: report of two cases with disparate courses and review of therapeutic options. Dig Dis Sci 44: 1148-1155, 1999.

25. Smith CS, Houston M, Jensen B, Mlinar K, Toulson C, Tillotson LG. A 32-year-old man with copious, watery diarrhea. N C Med J 62: 134-139, 2001.

26. Sycamnias J, Strahl B, Stride P, Chern B, Paranavithana L. A case of vasoactive intestinal polypeptideoma. N Z Med J 122: 64-68, 2009.

27. de Mestier L, Walter T, Brixi H, Lombard-Bohas C, Cadiot G. Sunitinib achieved fast and sustained control of VIPoma symptoms. Eur J Endocrinol 172: K1-K3, 2015.

The Internal Medicine is an Open Access article distributed under the Creative Commons Attribution-NonCommercial-NoDerivatives 4.0 International License. To view the details of this license, please visit (https://creativecommons.org/licenses/ by-nc-nd/4.0/).

(C) 2017 The Japanese Society of Internal Medicine http://www.naika.or.jp/imonline/index.html 